\title{
The multilayer-modified Stoney's formula for laminated polymer composites on a silicon substrate
}

\author{
Jin S. Kim ${ }^{\mathrm{a})}$ and Kyung W. Paik \\ Department of Materials Science and Engineering, Korea Advanced Institute of Science and Technology, \\ Taejon 305-701, Korea \\ Seung H. Oh \\ Department of Mechanical Engineering, Korea Advanced Institute of Science and Technology, \\ Taejon 305-701, Korea
}

(Received 17 June 1999; accepted for publication 16 August 1999)

\begin{abstract}
The thermomechanical behavior of multilayer structures is a subject of perennial interest. Stoney's formula has long been one of the most important tools for understanding thermomechanical stress for single-layered structures like spin-coated polyimides or deposited metal thin film on substrates. In today's microelectronics, however, as multilayer substrates have become widely available, the "modified version" of Stoney's formula for multilayer applications is not only useful but necessary. While the majority of reports in the literature have focused on single-layer analysis, in this study, we examined an extended usage of Stoney's formula for multilayer analysis. A simple model, the multilayer-modified Stoney's formula, which predicts the stress contribution of each individual layer is proposed and verified through experiments and numerical analysis. Using various kinds of materials employed in a typical lamination-based multichip module technology, the thermomechanical behavior of the lamination-based multilayer substrates was measured by a laser profilometry during thermal cycling. The measured values were compared with calculated values using the multilayer-modified Stoney's formula. (c) 1999 American Institute of Physics. [S0021-8979(99)05822-3]
\end{abstract}

\section{INTRODUCTION}

The thermomechanical behavior of multilayer substrates is a subject of perennial interest. The difference in the coefficient of thermal expansion (CTE) between substrate, polymer, and metal leads to complicated stress fields in multilevel interconnect structures. A vast amount of literature exists on this topic for mechanical structures. ${ }^{1-5}$ It is an important reliability and fabrication issue to realize costeffective and high-reliability electronic devices.

One of the most well-known formulas for thermomechanical stress analysis of thin film on much thicker substrates is Stoney's formula. ${ }^{6}$ The formula has long been one of the most important tools for understanding the thermomechanical phenomena in thin films in electronic devices. ${ }^{7-11}$ However, while the formula has been conveniently used for the last few decades, the original single-layer assumption of the formula has limited its applications mostly to singlelayered structures like spin-coated polyimides or deposited metal thin film on substrates.

In today's microelectronics, as multilayer substrates have become widely available, a "modified version" of Stoney's formula has become necessary. One important example of multilayer substrates in today's microelectronics is the lamination-based multichip module (MCM) substrates shown in Fig. 1. ${ }^{12,13}$ In the lamination process, a polymeric overlay film is overlaid on a silicon substrate using a polymeric adhesive, so the process involves at least doublelayered composite films consisting of the overlay film and

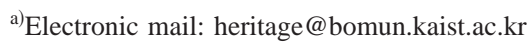

adhesive. When it comes to the thermal behavior of metal thin film interconnections not only on silicon wafers ${ }^{7-11}$ but also on multilayer substrates, a correct understanding of the thermal behavior of the multilayer substrates themselves is a necessary first step.

While the majority of reports in the literature have focused on single-layer analysis using Stoney's formula, we examined an extended usage of Stoney's formula for multilayer analysis. A few useful closed-form expressions have been developed for the multilayer analysis under certain sets of assumptions and using different approximations, but most of them have rarely been supported by experimental investigation. ${ }^{1-5}$ In this study, a simple model, the multilayer-modified Stoney's formula, which predicts the stress contribution of each individual layer was proposed and verified through experiments and numerical analysis. Using various kinds of materials employed in a typical laminationbased MCM-D technology, the thermomechanical behavior of the lamination-based multilayer substrates was measured by a laser profilometry during thermal cycling. The measured values were compared with calculated values using the multilayer-modified Stoney's formula.

\section{THEORY}

The first theoretical formula for the evaluation of stresses, arising in a thin film prepared on a thick substrate, was suggested by Stoney ${ }^{6}$ and is still widely used for stress calculation from the measured deformation of the substrate. This formula can be written as follows: 


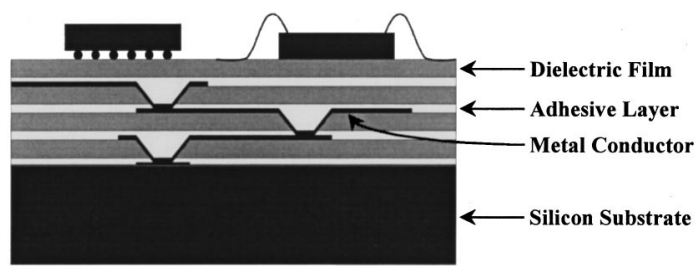

FIG. 1. Schematic diagram of the lamination-based silicon monolithic MCM-D substrates.

$$
\sigma_{f}=\frac{E_{s}}{6 R} \frac{t_{s}^{2}}{t_{f}}
$$

where $\sigma_{f}$ is the stress in the film, $E_{s}=E_{s}^{o} /\left(1-\nu_{s}^{o}\right)$ is the biaxial Young's modulus for the substrate material where $E_{s}^{o}$ and $\nu_{s}^{o}$ are the elastic modulus and the Poisson's ratio of the substrate material, respectively, $t_{f}$ and $t_{s}$ are the thickness of the substrate and the film, respectively, and $R$ is the radius of curvature. Note that Stoney's formula allows one to calculate the film stress directly from measured deflections without knowledge of the properties of the film. The factor $1 /(1$ $-\nu_{s}^{o}$ ) did not appear in Stoney's original results but was added in order to properly account for the biaxial stress field as discussed by Kinosita ${ }^{14}$ and more recently by Suhir. ${ }^{1}$

Stoney's formula can be used, as long as the mechanical properties of the film material are unavailable. Otherwise the formula

$$
\sigma_{f}=E_{f} \Delta \alpha \Delta T
$$

can be used, where $E_{f}$ is the biaxial Young's modulus and $\Delta \alpha=\alpha_{f}-\alpha_{s}$, where $\alpha_{f}$ and $\alpha_{s}$ are the CTEs for the film and substrate, respectively, and $\Delta T$ is the temperature excursion.

Meanwhile, the formulas for the curvature, $R$, can be obtained by equating formulas (1) and (2) as

$$
R=\frac{1}{E_{f} t_{f} \Delta \alpha}\left(\frac{E_{s} t_{s}^{2}}{6 \Delta T}\right)
$$

Furthermore, from formula (3) and the geometrical consideration of the curvature, i.e.,

$$
B=\frac{L_{s}^{2}}{8 R}
$$

the maximum bow value, $B$, can be obtained as

$$
B=\frac{3 L_{s}^{2}}{4}\left(\frac{E_{f} t_{f} \Delta \alpha \Delta T}{E_{s} t_{s}^{2}}\right),
$$

where $L_{s}$ is the scan length of laser profilometry and is $8 \mathrm{~cm}$ in this study.

According to formulas (1) and (5), the level of stress in a film is proportional to the maximum bow value as ${ }^{15}$

$$
\sigma_{f}=\left(\frac{4}{3 L_{s}^{2}}\right)\left(\frac{E_{s} t_{s}}{t_{f}}\right) \times B .
$$

Note that formulas (1) through (6) are only for singlelayered structures. For multilayer structures, we suggest the formula, $B=\Sigma B_{i}$, as the multilayer-modified Stoney's for-
TABLE I. Physical constants for the lamination-based MCM-D substrate materials; room temperature property values.

\begin{tabular}{lccccc}
\hline \hline Materials & Symbol & $E(\mathrm{GPa})$ & $\nu$ & $\alpha\left(10^{-6} /{ }^{\circ} \mathrm{C}\right)$ & $t(\mu \mathrm{m})$ \\
\hline Silicon & $\mathrm{Si}$ & 141 & 0.22 & 2.6 & 525 \\
Coverlay ${ }^{\mathrm{a}}$ & $\mathrm{E} 25 \mathrm{KH} 25$ & 0.5 & 0.37 & 60 & 50.8 \\
Ultem $^{\mathrm{b}}{ }^{\mathrm{b}} 1000$ & $\mathrm{U} 17$ & 3.9 & 0.35 & 31 & 17.3 \\
Ultem $^{\mathrm{b}}{ }^{\mathrm{b}} 1000 \mathrm{film}$ & $\mathrm{U} 50$ & 3.9 & 0.35 & 31 & 50.8 \\
Kapton ${ }^{\mathrm{c}}$ type 100 HN & $\mathrm{KH} 25$ & 2.6 & 0.34 & 20 & 25.4 \\
Kapton ${ }^{\mathrm{c}}$ type 200 HN & $\mathrm{KH} 50$ & 2.6 & 0.34 & 20 & 50.8 \\
Kapton ${ }^{\mathrm{c}}$ type 300 HN & KH75 & 2.6 & 0.34 & 20 & 76.2 \\
Kapton ${ }^{\mathrm{c}}$ type 500 HN & KH125 & 2.6 & 0.34 & 20 & 127.0 \\
Apical ${ }^{\mathrm{d}}$ & $\mathrm{AP} 25$ & 8.8 & 0.34 & 12 & 25.4 \\
\hline \hline
\end{tabular}

${ }^{\mathrm{a}}$ Coverlay ${ }^{\circledR}$ is the registered trademark of Toray, which consists of $25 \mu \mathrm{m}$ epoxy thermoset and $25 \mu \mathrm{m}$ Kapton film, hence, the symbol E25KH25.

${ }^{\mathrm{b}}$ Ultem ${ }^{\circledR}$ is the registered trademark of GE.

${ }^{\mathrm{c}}$ Kapton ${ }^{\circledR}$ is the registered trademark of DuPont.

${ }^{\mathrm{d}}$ Apical ${ }^{\circledR}$ is the registered trademark of Allied-Apical.

mula, where $B$ is the maximum bow value of a multilayer structure as a whole at a certain temperature, and $B_{i}$ is the amount of bowing caused by $i$ th layer at the same temperature and is calculated from the original Stoney's formula, formula (1). Formula (6) implies that when multiple thin films are deposited sequentially onto a much thicker substrate, each film causes a fixed amount of bowing to occur irrespective of the order in which the films are deposited, i.e., $B=\Sigma B_{i}$. From this concept and formula (5), we obtain

$$
B=\sum_{i=1}^{n} B_{f i}=\frac{3 L_{s}^{2}}{4} \sum_{i=1}^{n}\left(\frac{E_{f i} \alpha_{f i} t_{f i} \Delta T_{f i}}{E_{s} t_{s}^{2}}\right),
$$

where $E_{f i}, \alpha_{f i}, t_{f i}$ and $\Delta T_{f i}$ are the biaxial Young's modulus, coefficient of thermal expansion, thickness, and thermal excursion of the $i$ th-layer film, respectively. If formula (7) is differentiated with respect to temperature and rearranged, the result is the slope of the thermal cycling curve

$$
\frac{d B}{d T}=\frac{3 L_{s}^{2}}{4} \sum_{i=1}^{n}\left(\frac{E_{f i} \alpha_{f i} t_{f i}}{E_{s} t_{s}^{2}}\right) .
$$

Note that formula (8) is readily applicable for the lamination-based multilayer MCM-D substrates using a la-

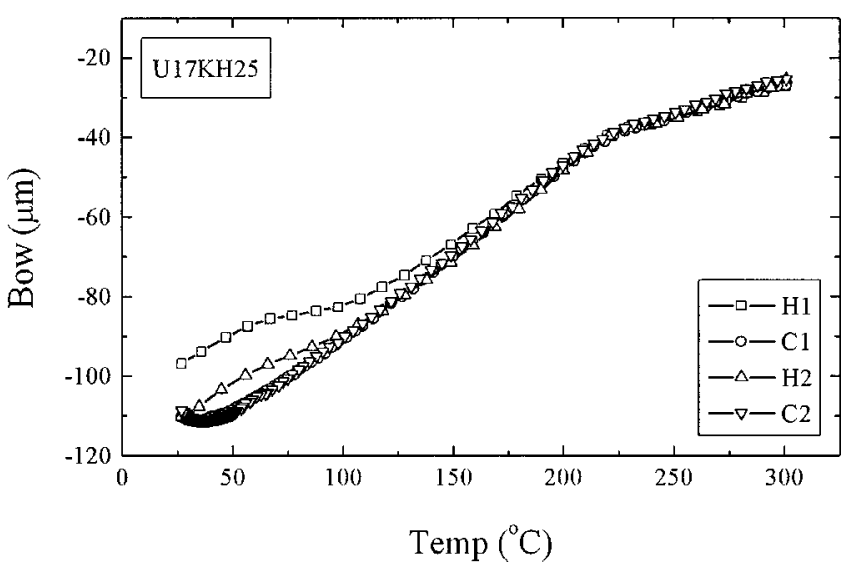

FIG. 2. Thermal behavior of the Ultem/Kapton composite consisting of 17.3 $\mu \mathrm{m}$ Ultem thermoplastic and $25.4 \mu \mathrm{m}$ Kapton polyimide film on a silicon substrate. $\mathrm{H} 1=1$ st heating cycle, $\mathrm{C} 1=1$ st cooling cycle, etc. 


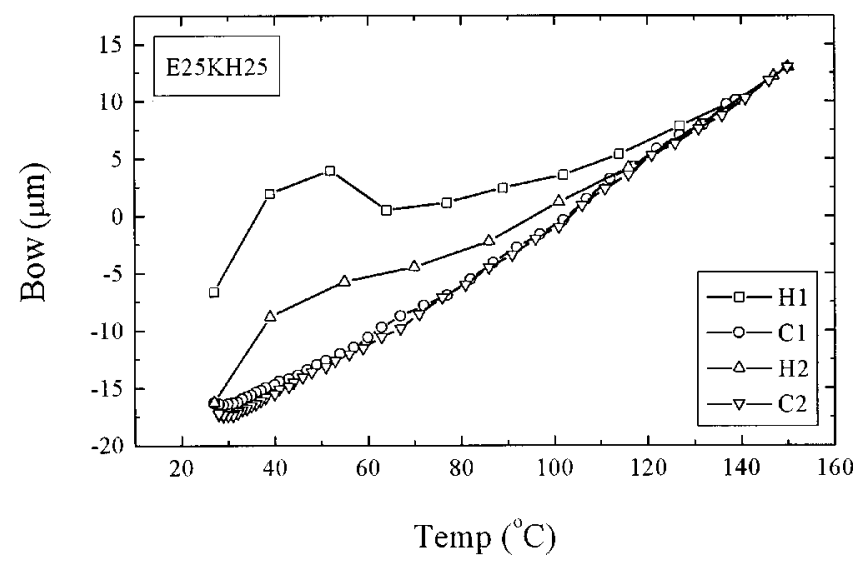

FIG. 3. Thermal behavior of Coverlay film consisting of $25.4 \mu \mathrm{m}$ epoxy thermoset and $25.4 \mu \mathrm{m}$ Kapton polyimide film on a silicon substrate. H1 $=1$ st heating cycle, $\mathrm{C} 1=1$ st cooling cycle, etc.

ser profilometry. Formulas (7) and (8), the multilayermodified Stoney's formulas, imply that the composite stress and bowing of multilayer structures are due to the individual contribution of each individual layer.

\section{EXPERIMENT}

Thermal cycling was performed on the laminated substrates composed of various kinds and thickness of adhesives and overlay films (Table I). Stress test structures were fabricated on $10 \mathrm{~cm}$ diameter by $525-\mu \mathrm{m}$-thick (001) single crystal silicon wafers. Materials used in a typical laminationbased MCM-D substrate were applied to the substrate: 17.3 and $50.8 \mu \mathrm{m}$ of Ultem 1000 as thermoplastic adhesives, 25.4 $\mu \mathrm{m}$ epoxy as a thermoset adhesive, 25.4, 50.8, 75.2 and $127.0 \mu \mathrm{m}$ Kapton polyimide films as overlay films, and 25.4 $\mu \mathrm{m}$ Apical polyimide film as an alternative overlay film of Kapton film. Physical constants of the substrate, adhesive polymers and overlay polymers are summarized in Table I. Note that the epoxy thermoset adhesive was provided in Coverlay film consists of the $25.4 \mu \mathrm{m}$ epoxy thermoset and $25.4 \mu \mathrm{m}$ Kapton film, and the physical properties of Coverlay film, the epoxy/Kapton composite, were given in Table I.

The composites were laminated to the silicon substrate by heat and pressure at $310^{\circ} \mathrm{C} / 55 \mathrm{psi} / 60 \mathrm{~min}$ for the Ultem thermoplastic adhesive and at $150{ }^{\circ} \mathrm{C} / 50 \mathrm{psi} / 40 \mathrm{~min}$ for the epoxy thermoset adhesive. The maximum bow values were measured during thermal cycling by a laser profilometry. ${ }^{9}$ The test structures were thermally cycled between room temperature and $300^{\circ} \mathrm{C}$ for the Ultem thermoplastic adhesive, and between room temperature and $150^{\circ} \mathrm{C}$ for the epoxy thermoset adhesive. The commercial software MSC/ NASTRAN (Ref. 16) was implemented as a simulation tool

TABLE II. Comparison of the slopes of the Ultem/Kapton and epoxy/ Kapton composites on a silicon substrate.

\begin{tabular}{lccc}
\hline \hline Composite & $\begin{array}{c}\text { Measured } \\
\left.\mu \mathrm{m} /{ }^{\circ} \mathrm{C}\right)\end{array}$ & $\begin{array}{c}\text { Modified-Stoney } \\
\left(\mu \mathrm{m} /{ }^{\circ} \mathrm{C}\right)\end{array}$ & $\begin{array}{c}\text { Numerical } \\
\left(\mu \mathrm{m} /{ }^{\circ} \mathrm{C}\right)\end{array}$ \\
\hline $\mathrm{U} 17 \mathrm{KH} 25$ & 0.4069 & 0.4936 & 0.4170 \\
$\mathrm{E} 25 \mathrm{KH} 25$ & 0.2429 & 0.2104 & 0.1918 \\
\hline \hline
\end{tabular}

TABLE III. Comparison of the slopes of the Ultem/Kapton and Ultem/ Apical composites on a silicon substrate.

\begin{tabular}{lccc}
\hline \hline Composite & $\begin{array}{c}\text { Measured } \\
\left(\mu \mathrm{m} /{ }^{\circ} \mathrm{C}\right)\end{array}$ & $\begin{array}{c}\text { Modified-Stoney } \\
\left(\mu \mathrm{m} /{ }^{\circ} \mathrm{C}\right)\end{array}$ & $\begin{array}{c}\text { Numerical } \\
\left(\mu \mathrm{m} /{ }^{\circ} \mathrm{C}\right)\end{array}$ \\
\hline $\mathrm{U} 17 \mathrm{KH} 25$ & 0.4069 & 0.4936 & 0.4170 \\
$\mathrm{U} 17 \mathrm{AP} 25$ & 0.4694 & 0.5730 & 0.4869 \\
\hline \hline
\end{tabular}

where plane strain element was utilized for the expression of the composite films. The other conditions were: the number of elements was 800, the maximum aspect ratio was 23.1, boundary conditions were pinned and simply supported, and loading condition was thermal loading.

\section{RESULTS AND DISCUSSION}

Figure 2 shows the thermal cycling result for the Ultem/ Kapton composite consisting of $17.3 \mu \mathrm{m}$ Ultem thermoplastic and $25.4 \mu \mathrm{m}$ Kapton film on a silicon substrate. The maximum bow value at room temperature after fabrication and storage for $48 \mathrm{~h}$ was about $110 \mu \mathrm{m}$ and was due to both intrinsic and thermal stresses. ${ }^{17,18}$ The intrinsic stress (or bowing) relaxed during the initial stage of the first heat cycle (H1), then the bow value increased by about $10 \%$ on cooling (C1) as a result of the CTE mismatch. Reproducible hysteresis was obtained during further cycles. The curve deflected somewhat above $217^{\circ} \mathrm{C}$ reflecting the presence of the Ultem layer whose viscoelastic behavior would be expected to relax the stress above the glass transition temperature, $T_{g}$. The $T_{g}$ of Ultem 1000 is approximately $217^{\circ} \mathrm{C}$, so low elastic modulus and viscoelastic behavior are expected above $T_{g}$. A small amount of hysteresis and linear slopes indicate that the deformation was primarily elastic below $T_{g}$. No other transitions were observed since the $T_{g}$ for Kapton is above 400 ${ }^{\circ} \mathrm{C}$.

Figure 3 shows the thermal cycling result for Coverlay film consisting of $25.4 \mu \mathrm{m}$ epoxy thermoset and $25.4 \mu \mathrm{m}$ Kapton film on a silicon substrate. The maximum substrate bow value at room temperature after fabrication and storage for $48 \mathrm{~h}$ was about $15 \mu \mathrm{m}$. Intrinsic stress relaxed during the first half of the heating cycle (H1), then the bow value increased by almost $80 \%$ on cooling $(\mathrm{C} 1)$ as a result of the CTE mismatch. The intrinsic stress during the first heating cycle was presumably due to moisture absorption, ${ }^{19}$ because polymer dielectric materials absorb some level of moisture depending on the relative humidity of storage. Reproducible hysteresis was obtained during further cycles.

Table II compares the measured values of the slope $(d B / d T)$ with the calculated values from the multilayermodified Stoney's formula and numerical analysis. The cool-

TABLE IV. Comparison of the slopes of the Ultem/Kapton composite with different adhesive thickness on a silicon substrate.

\begin{tabular}{lccc}
\hline \hline Composite & $\begin{array}{c}\text { Measured } \\
\left(\mu \mathrm{m} /{ }^{\circ} \mathrm{C}\right)\end{array}$ & $\begin{array}{c}\text { Modified-Stoney } \\
\left(\mu \mathrm{m} /{ }^{\circ} \mathrm{C}\right)\end{array}$ & $\begin{array}{c}\text { Numerical } \\
\left(\mu \mathrm{m} /{ }^{\circ} \mathrm{C}\right)\end{array}$ \\
\hline $\mathrm{U} 17 \mathrm{KH} 25$ & 0.4069 & 0.4936 & 0.4170 \\
$\mathrm{U} 50 \mathrm{KH} 25$ & 1.0329 & 1.0783 & 0.9703 \\
\hline \hline
\end{tabular}


TABLE V. Comparison of the slopes of the Ultem/Kapton composite with various overlay film thickness on a silicon substrate.

\begin{tabular}{lccc}
\hline \hline Composite & $\begin{array}{c}\text { Measured } \\
\left(\mu \mathrm{m} /{ }^{\circ} \mathrm{C}\right)\end{array}$ & $\begin{array}{c}\text { Modified-Stoney } \\
\left(\mu \mathrm{m} /{ }^{\circ} \mathrm{C}\right)\end{array}$ & $\begin{array}{c}\text { Numerical } \\
\left(\mu \mathrm{m} /{ }^{\circ} \mathrm{C}\right)\end{array}$ \\
\hline U50KH25 & 1.0329 & 1.0783 & 0.9703 \\
U50KH50 & 1.1083 & 1.2586 & 1.1561 \\
U50KH75 & 1.2053 & 1.4375 & 1.3526 \\
U50KH125 & 1.5124 & 1.7911 & 1.7745 \\
\hline \hline
\end{tabular}

ing portions of the first cycles (C1) were taken from Figs. 2 and 3 to measure the slope to minimize the intrinsic stress effect. The analysis assumed linear elastic behavior and used room temperature physical property values (Table I). It is generally assumed that the physical properties of polymer materials are constants in a low and small temperature range below the glass transition temperatures, so the slopes were measured in the temperature range below the $T_{g}$. Insignificant hysteresis and linear slopes imply predominantly elastic deformation. Table II shows that regardless of adhesive types, whether thermoplastics or thermosets were used as a lamination adhesive, the proposed multilayer-modified Stoney's formula was well applied in the temperature range below $T_{g}$.

In all cases using Ultem thermoplastic, as we will see from Tables II through V, the calculated values using the multilayer-modified Stoney's formula as well as the numerical model exceeded by a small amount the measured values with constant deviation. This was mainly due to the dependence of physical properties of Ultem thermoplastic on the measurement environment, or the slightly imperfect elastic behavior of Ultem thermoplastic even below $T_{g}$.

Figure 4 shows the thermal cycling result for the Ultem/ Apical composite consisting of $17.3 \mu \mathrm{m}$ Ultem thermoplastic and $25.4 \mu \mathrm{m}$ Apical film on a silicon substrate, where Apical polyimide film was used as an alternative overlay film of Kapton film. The thermal behavior was much the same as that of the Ultem/Kapton composite on a silicon substrate in Fig. 2. The curve deflected somewhat above $217^{\circ} \mathrm{C}$ reflecting the presence of Ultem thermoplastic as did for the Ultem/

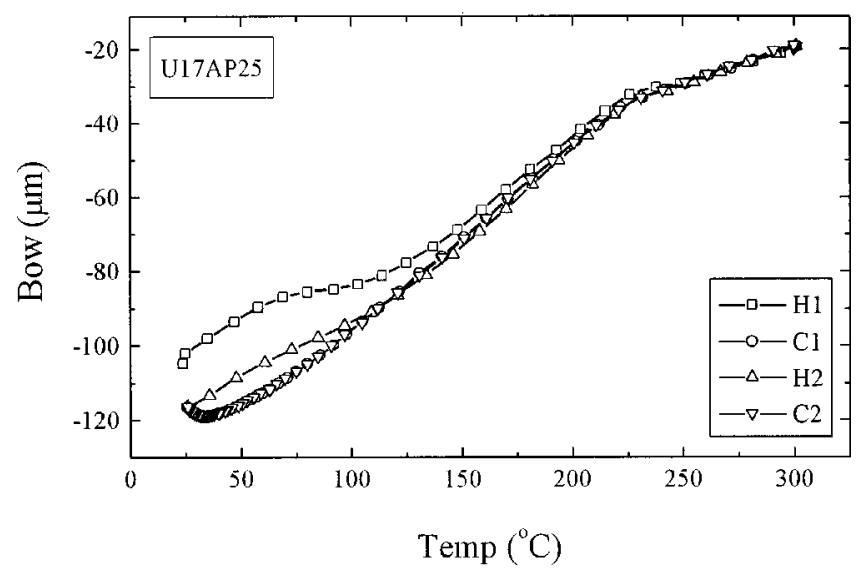

FIG. 4. Thermal behavior of the Ultem/Apical composite consisting of 17.3 $\mu \mathrm{m}$ Ultem thermoplastic and $25.4 \mu \mathrm{m}$ Apical polyimide film on a silicon substrate. $\mathrm{H} 1=1$ st heating cycle, $\mathrm{C} 1=1 \mathrm{st}$ cooling cycle, etc.

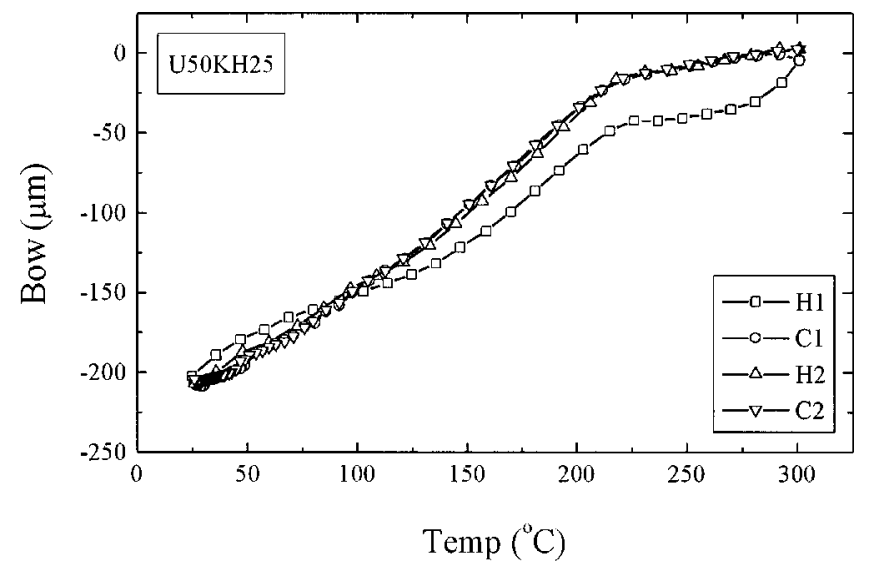

FIG. 5. Thermal behavior of the Ultem/Kapton composite consisting of 50.8 $\mu \mathrm{m}$ Ultem thermoplastic and $25.4 \mu \mathrm{m}$ Kapton polyimide film on a silicon substrate. $\mathrm{H} 1=1$ st heating cycle, $\mathrm{C} 1=1$ st cooling cycle, etc.

Kapton composite. The maximum substrate bow value at room temperature after fabrication and storage for $48 \mathrm{~h}$ was about $120 \mu \mathrm{m}$. Table III summarizes the measured values of the slope $(d B / d T)$ from Figs. 2 and 4 . The comparison of the measured values and the calculated values from the multilayer-modified Stoney's formula and numerical analysis indicates that the proposed formula could be applied to the overlay films with different physical properties.

Figure 5 shows the thermal cycling result for the Ultem/ Kapton composite consisting of $50.8 \mu \mathrm{m}$ Ultem thermoplastic and $25.4 \mu \mathrm{m}$ Kapton film on a silicon substrate. The thermal behavior was much the same as that of $17.3 \mu \mathrm{m}$ Ultem thermoplastic case in Fig. 2, except the increased size of hysteresis loop at high temperature region above $T_{g}$. This is mainly due to the viscoelastic behavior of Ultem thermoplastic above $T_{g}$, now that the amount of Ultem thermoplastic was increased from 17.3 to $50.8 \mu \mathrm{m}$ in Fig. 5. Also, the maximum substrate bow value at room temperature after fabrication and storage for $48 \mathrm{~h}$ increased to about $210 \mu \mathrm{m}$ because of the increased amount of Ultem thermoplastic. Table IV summarizes the measured values of the slope $(d B / d T)$ from Figs. 2 and 5 to see the adhesive thickness

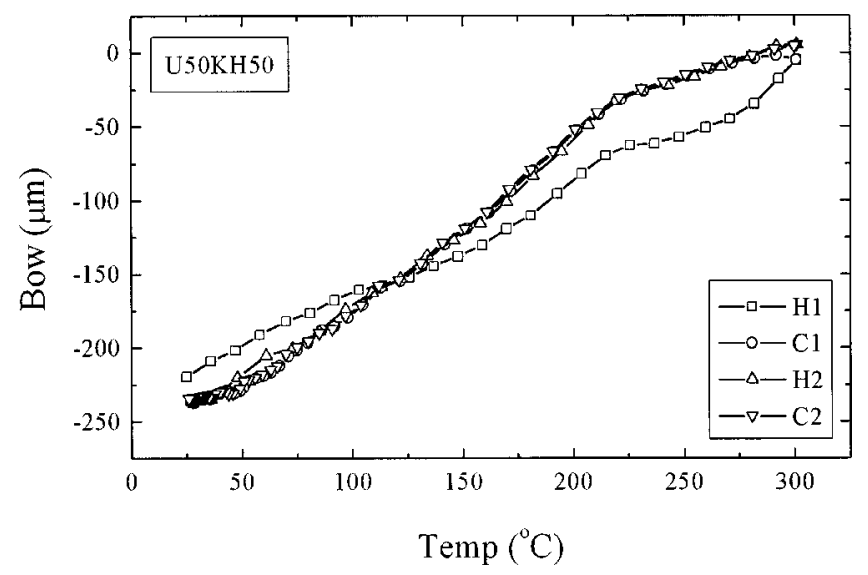

FIG. 6. Thermal behavior of the Ultem/Kapton composite consisting of 50.8 $\mu \mathrm{m}$ Ultem thermoplastic and $50.8 \mu \mathrm{m}$ Kapton polyimide film on a silicon substrate. $\mathrm{H} 1=1$ st heating cycle, $\mathrm{C} 1=1$ st cooling cycle, etc. 


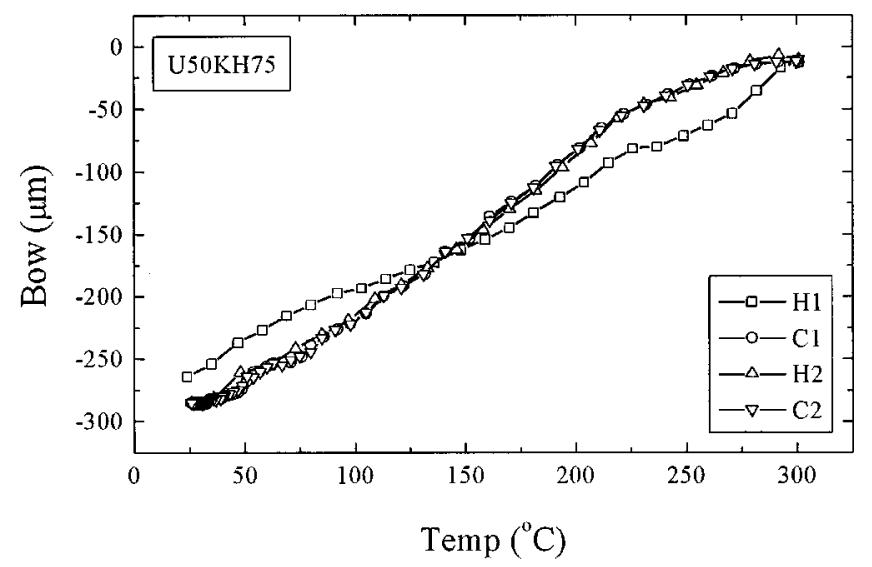

FIG. 7. Thermal behavior of the Ultem/Kapton composite consisting of 50.8 $\mu \mathrm{m}$ Ultem thermoplastic and $76.2 \mu \mathrm{m}$ Kapton polyimide film on a silicon substrate. $\mathrm{H} 1=1$ st heating cycle, $\mathrm{C} 1=1$ st cooling cycle, etc.

effect. The comparison of the measured values and the calculated values from the multilayer-modified Stoney's formula and numerical analysis suggests that the proposed formula can be used regardless of adhesive thickness.

Figures 5 through 8 show the thermal cycling results for the Ultem/Kapton composite on a silicon substrate with various Kapton film thickness. The 25.4, 50.8, 75.2, and 127.0 $\mu \mathrm{m}$ Kapton films were overlaid using 50.8_ $\mu \mathrm{m}$ Ultem adhesive. As summarized in Table $\mathrm{V}$, the agreement was well established between measured and calculated values regardless of the overlay film thickness.

For more realistic modeling of the lamination-based MCM-D substrates, where the fabrication of upper-layer dielectrics must be accomplished at the temperatures below the temperatures of low-layer dielectrics, ${ }^{13}$ the Ultem/Kapton composite and Coverlay film were laminated sequentially on a silicon substrate at 310 and $150{ }^{\circ} \mathrm{C}$, respectively. Figure 9 shows the thermal behavior of such a multilayer structure, a silicon/Ultem/Kapton/epoxy/Kapton (Si/U50KH25/ E25KH25) structure, where the $50.8 \mu \mathrm{m}$ Ultem thermoplastic and the $25.4 \mu \mathrm{m}$ epoxy thermoset were used as lamination adhesives, and the $25.4 \mu \mathrm{m}$ Kapton films were used as

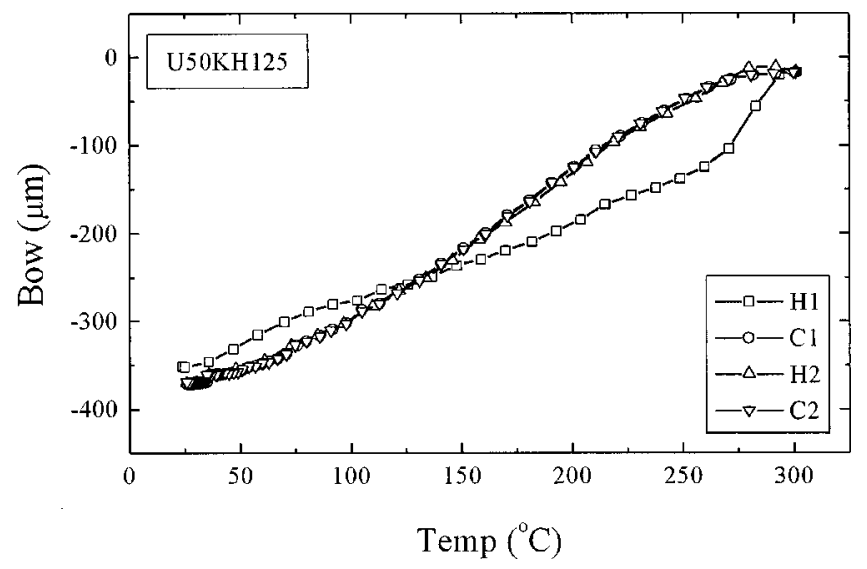

FIG. 8. Thermal behavior of the Ultem/Kapton composite consisting of 50.8 $\mu \mathrm{m}$ Ultem thermoplastic and $127.0 \mu \mathrm{m}$ Kapton polyimide film on a silicon substrate. $\mathrm{H} 1=1$ st heating cycle, $\mathrm{C} 1=1$ st cooling cycle, etc.

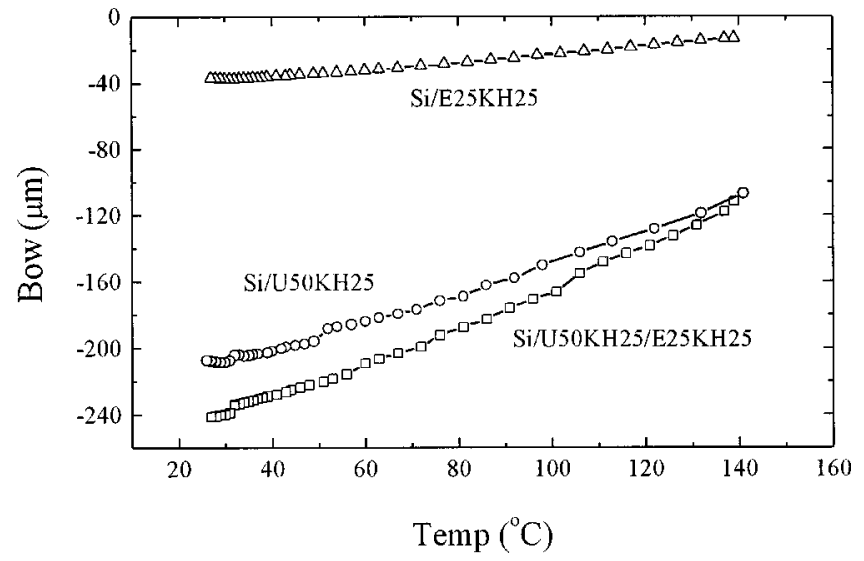

FIG. 9. Thermal behavior of the silicon/Ultem/Kapton (Si/U50KH25), silicon/epoxy/Kapton (Si/E25KH25), and silicon/Ultem/Kapton/epoxy/ Kapton (Si/U50KH25/E25KH25) structures. Only the first cooling curves (C1) are presented.

overlay films. Only the first cooling curves are presented in Fig. 9. Figure 9 also shows the thermal behavior of the silicon/Ultem/Kapton (Si/U50KH25) and silicon/epoxy/ Kapton ( $\mathrm{Si} / \mathrm{E} 25 \mathrm{KH} 25)$ structures. At each temperature, it is obvious that the relation, $B=\Sigma B_{i}$, was well established, i.e., each individual composite layer contributes independently a fixed amount of bending to the multilayer structure as suggested by the multilayer-modified Stoney's formula.

Note that one of the key thermomechanical issues during the MCM-D substrate fabrication is substrate bowing, and the other important concern is the thermal stress caused by the CTE mismatch. While the thermal stress causes mechanical failure of films, such as adhesion reduction, contact peeloff, and variations in electrical properties, ${ }^{11,20}$ substrate bowing makes the fabrication process difficult, for example, vacuum mounting for handling and substrate sawing after fabrication. ${ }^{20}$ It also causes a misregistration problem during photolithography and fine-pitch wire bonding, a stress concentration problem in internal structures such as via, ${ }^{15}$ and flip chip bump failure due to repeated thermal loading. The agreement between the experimental results and formulas (7) and (8) suggests that the amount of multilayer substrate bowing can be properly understood when the contribution of each layer is combined through the multilayer-modified Stoney's formula.

\section{CONCLUSION}

While the majority of reports in the literature have focused on single-layer analysis using the original Stoney's formula, in this study, we examined the extended usage of Stoney's formula for the multilayer analysis. A simple model, the multilayer-modified Stoney's formula, which predicts the stress contribution of each individual layer was proposed and verified through experiments and numerical analysis. Using various kinds of materials employed in a typical lamination-based MCM-D technology, the thermomechanical behavior of the lamination-based multilayer substrates was measured by a laser profilometry during thermal cycling. The agreement between the experimental and calculated re- 
sults suggests that the amount of multilayer substrate bowing can be correctly described when the contribution of each layer is combined through the multilayer-modified Stoney's formula.

${ }^{1}$ E. Suhir, J. Appl. Mech. 55, 143 (1988).

${ }^{2}$ J. Vilms and D. Kerps, J. Appl. Phys. 53, 1536 (1982).

${ }^{3}$ T. Pan and Y. Pao, J. Electron. Packaging 112, 30 (1990).

${ }^{4}$ A. Cifuentes, J. Electron. Packaging 113, 425 (1991).

${ }^{5}$ B. Mirman, J. Electron. Packaging 114, 384 (1992).

${ }^{6}$ G. Stoney, Proc. R. Soc. London, Ser. A 82, 172 (1909).

${ }^{7}$ D. Gardner and P. Flinn, IEEE Trans. Electron Devices ED-35, 2160 (1988).

${ }^{8}$ D. Gardner and P. Flinn, J. Appl. Phys. 67, 1831 (1990).

${ }^{9}$ P. Flinn, D. Gardner, and W. Nix, IEEE Trans. Electron Devices ED-34, 689 (1987).

${ }^{10}$ P. Flinn, J. Mater. Res. 6, 1498 (1991).
${ }^{11}$ H. Liu and S. Murarka, J. Appl. Phys. 72, 3458 (1992).

${ }^{12}$ R. Fillion, W. Daum, E. Wildi, and E. Kaminsky, Proceedings of the International Symposium on Microelectronics (ISHM, San Francisco, CA, 1992), p. 391.

${ }^{13}$ H. Cole, B. Gorowitz, T. Gorczyca, R. Wojnarowski, and J. Lupinski, Mater. Res. Soc. Symp. Proc. 264, 43 (1992).

${ }^{14}$ K. Kinosita, Thin Solid Films 12, 17 (1972).

${ }^{15}$ I. Kitazawa, S. Mino, and Y. Hibino, IEEE Trans. Compon., Packag. Manuf. Technol., Part A 20, 327 (1997).

${ }^{16}$ MSC/NASTRAN User's Manual (MacNeal-Schwendler Co., Los Angeles, CA, 1996)

${ }^{17}$ J. Jou, L. Hsu, and L. Chang, Thin Solid Films 201, 253 (1991).

${ }^{18}$ S. Bruck and D. Knorr, Mater. Res. Soc. Symp. Proc. 264, 251 (1992).

${ }^{19}$ A. Voloshin, P. Tsao, and R. Pearson, J. Electron. Packaging 120, 314 (1998).

${ }^{20}$ C. Chao, K. Scholz, J. Leibovitz, M. Cobarruviaz, and C. Chang, IEEE Trans. Compon., Hybrids, Manuf. Technol. CHMT-12, 180 (1989). 